\title{
Den Asthmagenen auf der Spur
}

\section{Daß Asthma im Kindes- alter zu einem erheblichen Anteil auf genetische Ursachen zurückgeht, ist schon seit längerem bekannt. Eine britisch- australische Arbeits- gruppe ist jetzt auf der Suche nach den ver- antwortlichen Genen einen großen Schritt vorangekommen.}

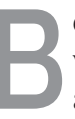
ei 223 Kindern aus 80 Familien wurde das gesamte Genom nach asthmadeterminierenden Erbanlagen abgesucht. Die Genomanalyse wurde dann in Beziehung zu folgenden vier Asthma- und Atopiemarkern gesetzt: dem IgE-Spiegel im Serum, dem STI (skin test index), der Eosinophilenzahl im peripheren Blut sowie der bronchialen Reagibilität (auf Methacholin). Dabei wurden sowohl Familien mit atopischer Disposition als auch solche ohne allergische Familienmitglieder in die Studie aufgenommen, um Assoziationen zwischen kindlichem Asthma und bestimmten Genen besser herausfiltern zu können.

Das mittlere Alter der Kinder betrug 12,6 Jahre. 12\% litten unter Asthma. $52 \%$ waren atopisch, 36\% nicht-atopisch, bei $12 \%$ lag ein Intermediärstadium vor.

Zur Analyse wurde auch die Geschwisterpaartechnik nach HasemanElston angewandt: Es ergaben sich insgesamt 172 Geschwisterpaare. Bei 44 Paaren waren beide Geschwister atopisch, in 87 Fällen nur eines der Kinder und bei 41 Paaren waren beide Geschwister nicht atopisch. Insgesamt wurden sechs Regionen im Genom gefunden, die mit einem der Atopiepara- meter assoziiert waren, und zwar auf den Chromosomen 4, 6, 7, 11, 13 und 16. Die Veränderungen auf Chromosom 11 und 16 waren dabei mit einem erhöhten IgE-Spiegel korreliert.

Bei den Chromosomen 4 und 7 bestand eine Assoziation mit der bronchialen Hyperreagibilität. Die Veränderungen auf Chromosom 6 gingen mit einer erhöhten Eosinophilenzahl einher und die auf Chromosom 13 mit einem atopischen Phänotyp in der Geschwisterpaaranalyse.

Mit den Loci der sechs Chromosomen sind nach Ansicht der Autoren erstmals Genorte mit einer sicheren Assoziation zu kindlichem Asthma nachgewiesen worden. Allerdings dürften unter den zahlreichen Loci im menschlichen Genom, die bisher noch nicht identifiziert sind, weitere Atopie- bzw. Asthmagene zu finden sein.

(zo)

\section{Kommentar}

Asthma ist im Kindesalter größtenteils mit Atopie assoziiert. Genetische Trennungsanalysen weisen auf die Präsenz von atopie- und IgE-Niveau-beeinflussenden Majorgenen hin. Durch positionales Klonen und die Untersuchung von Kandidatengenen wird versucht, diese zu identifizieren.

Die von der australischen Arbeitsgruppe durchgeführte genomweite Suche nach asthmadeterminierenden Erbanlagen zeigt potentielle Bindungen zu autosomalen Markern auf Chromosom 4, 6, 7, 11, 13 und 16. Verschiedenen Gene sind offenbar mit unterschiedlichen Phänotypen assoziiert. Die molekulargenetische Methodik ermöglicht ein besseres Verständnis und neuen Zugang zu der genetischen Prädisposition des atopischen Asthma.

Korrespondenzadresse:

Dr. med. R. Kehrt, Med. Fakultät der HumboldtUniversität zu Berlin, Virchow-Klinikum, Abt. Pädiatrie, Augustenburger Platz 1, D-13353 Berlin.

Quelle: Daniels SE, Bhattacharrya S, James A et al. A genome-wide search for quantitative trait loci underlying asthma. Nature 1996; 383: 247-50. 